\title{
Comparison of automatic airway analysis function of Invivo5 and Romexis software
}

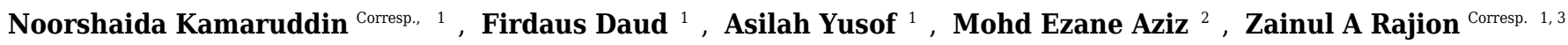 \\ ${ }^{1}$ School of Dental Sciences, Universiti Sains Malaysia, Kota Bharu, Kelantan, Malaysia \\ 2 School of Medical Sciences, Universiti Sains Malaysia Health Campus, Kota Bharu, Kelantan, Malaysia \\ 3 College of Dentistry, King Saud University, Riyadh, Riyadh, Saudi Arabia \\ Corresponding Authors: Noorshaida Kamaruddin, Zainul A Rajion \\ Email address: sha_e0220@yahoo.com, zar5057@gmail.com
}

Background. Visualization and calculation of the airway dimensions are important because an increase of airway resistance may lead to life-threatening emergencies. The visualization and calculation of the airway are possible using radiography technique with their advance software. The aim of this study was to compare and to test the reliability of the measurement of the upper airway volume and minimum area using airway analysis function in two software. Methods. The sample consisted of 11 cone-beam computed tomography (CBCT) scans data, evaluated using the Invivo5 (Anatomage) and Romexis (version 3.8.2.R, Planmeca) software which afford image reconstruction, and airway analysis. The measurements were done twice with one week gap between the two measurements. The measurement obtained was analyzed with t-tests and intraclass correlation coefficient (ICC), with confidence intervals (Cl) was set at 95\%. Results. From the analysis, the mean reading of volume and minimum area is not significantly different between Invivo5 and Romexis. Excellent intrarater reliability values were found for the both measurement on both software, with ICC values ranging from 0.940 to 0.998 . Discussion. The results suggested that both software can be used in further studies to investigate upper airway, thereby contributing to the diagnosis of upper airway obstructions. 


\section{Comparison of Automatic Airway Analysis Function of Invivo5 2 and Romexis Software}

3 Noorshaida Kamaruddin ${ }^{1}$, Firdaus Daud ${ }^{1}$, Asilah Yusof ${ }^{1}$, Mohd Ezane Aziz ${ }^{2}$, Zainul Ahmad

4 Rajion $^{1,3}$

$5{ }^{1}$ School of Dental Sciences, Universiti Sains Malaysia Health Campus, 16150 Kubang Kerian,

6 Kelantan, Malaysia.

$7 \quad{ }^{2}$ School of Medical Sciences, Universiti Sains Malaysia Health Campus, 16150 Kubang Kerian

8 Kelantan, Malaysia.

$9{ }^{3}$ College of Dentistry, King Saud bin Abdulaziz University for Health Sciences, Riyadh, Saudi

10 Arabia.

11

12 Corresponding Author:

13 Zainul Ahmad Rajion ${ }^{1,3}$

14 School of Dental Sciences, Universiti Sains Malaysia Health Campus, 16150 Kubang Kerian, Kelantan, 15 Malaysia.

16 Email address: zar5057@gmail.com 


\section{Abstract}

18 Background. Visualization and calculation of the airway dimensions are important because an calculation of the airway are possible using radiography technique with their advance software. The aim of this study was to compare and to test the reliability of the measurement of the upper airway volume and minimum area using airway analysis function in two software. Methods. The sample consisted of 11 cone-beam computed tomography (CBCT) scans data, evaluated using the Invivo5 (Anatomage) and Romexis (version 3.8.2.R, Planmeca) software which afford image reconstruction, and airway analysis. The measurements were done twice with one week gap between the two measurements. The measurement obtained was analyzed with t-tests and intraclass correlation coefficient (ICC), with confidence intervals (CI) was set at $95 \%$.

Results. From the analysis, the mean reading of volume and minimum area is not significantly different between Invivo5 and Romexis. Excellent intrarater reliability values were found for the both measurement on both software, with ICC values ranging from 0.940 to 0.998 .

Discussion. The results suggested that both software can be used in further studies to investigate upper airway, thereby contributing to the diagnosis of upper airway obstructions.

\section{Introduction}

The airway is a system that consists of tubes that convey inhaled air from the nose and mouth into the lungs. The skeletal support for airway is superiorly provided by the cranial base, posteriorly provided by the spine, anterosuperiorly provided by nasal septum, and anteriorly provided by the jaws and hyoid bone. An obstruction of the upper airway will increase airway resistance and can be minor or life-threatening emergencies which require immediate medical attention. Due to this reason, airway obstructions become attentive. Therefore, visualization and calculation of the airway dimensions are important. Airway obstruction is not diagnosed with imaging, however, imaging plays a role in the anatomic assessment of the airway and adjacent structures as imaging can identify the patients with airways who are at risk for obstruction. The upper airway can be visualized on conventional computed tomography $(\mathrm{CT})$, cone beam CT $(\mathrm{CBCT})$ and magnetic resonance imaging (MRI).

\section{CBCT and Image Analysis}

CBCT systems have been developed specifically for the maxillofacial region with the advantage of the reduced radiation doses compared with conventional CT (Ghoneima and Kula, 2013). Accurate and easy evaluation of the airway anatomy has been possible using those CBCT systems (El and Palomo, 2010). There were many studies (Feng et al., 2015; Glupker et al., 2015; Iwasaki et al., 2009; Kim et al., 2010; Camacho et al., 2014; Zinsly et al., 2010; Ogawa et al., 2005) of the upper airway were analyzed or assessed using CBCT. The next level up of CBCT is the advanced software tools involve airway tracing features that give the user the capability to delineate the airway's boundaries, measure its volume, and calculate and locate the minimum area (Chenin, 2015).

Although numerous methods with 2-dimensional (2D) cephalograms, providing limited data such as linear and angular has been proposed for upper airway studies, there were studies that evaluate the airway have introduced the use of CBCT, which made the 3D diagnosis of the 
59

60

61

62

63

64

65

66

67

68

69

patient became more accessible in dentistry. The segmentation of the airway can be done manually or automatically. Manual segmentation seems to be the most accurate method and allows for the most operator control (El and Palomo, 2010). Manual segmentation needs the operator to delineate the airway slice by slice and render the data into a 3D volume for analysis. (Schendel and Hatcher, 2010) have shown that the measurement of the 3D airway from CBCT data using a semi-assisted software program is accurate, reliable, and fast. While automatic segmentation can be done by differentiating structures with different density values as done by (Shi et al., 2006) which applied a simple grayscale thresholding based method to segment and measure the upper airway using CBCT.

Accuracy and reliability of airway measurements for volume and minimum area in CBCT images have been tested. (Lenza et al., 2010) had compared the linear, area, and volumetric measurements by two examiners and found no significant differences. (Aboudara et al., 2009) did a study to compare the nasopharyngeal airway size between a lateral head film and a CBCT scan in adolescent subjects and found that there is a significant positive relationship between nasopharyngeal airway size on a head film and its true volumetric size from a CBCT scan. (Ghoneima and Kula, 2013) had investigated the accuracy of CBCT airway measurements by scanning the actual volume of an airway model. The results of their study showed that the CBCT digital measurements of the airway volume and the minimum area of the airway are reliable and accurate.

Automatic segmentation of the airway is significantly faster and more practical than manual segmentation and had been found that it was reliable and accurate, but the reliability and reproducibility of the method with commercially available programs were less tested. The aim of this current study was to compare and to test the reliability of the measurement of upper airway volume and minimum area using airway analysis function in two software; Invivo5 (Anatomage) and Romexis (version 3.8.2.R, Planmeca).

\section{Materials \& Methods}

This retrospective study was done at School of Dental Sciences, University Sains Malaysia, Health Campus, Kubang Kerian Kelantan. The sample size was calculated using G Power calculator with $\alpha$ (probability error) of $0.05,80 \%$ power and effect size of 0.7 . From calculation, 11 samples would be sufficient. 11 CBCT scans data were selected from the dental clinic database system, School of Dental Sciences. The CBCT scan data with the defined airway was not clear or the airway not fully contained in the image or the image containing artifacts was excluded. The entire CBCT scan data was obtained from Planmeca Promax 3D Mid (Planmeca, Helsinki, Finland) with $90 \mathrm{kV}, 8 \mathrm{~mA}$ and $13.822 \mathrm{~s}$ technical factor. The scans were done using a field of view (FOV) of $160 \mathrm{~mm}, 400 \mu \mathrm{m}$ voxel size and 454 x 454 x $436 \mathrm{~mm}^{3}$ image size. All the 11 CBCT scan images were analysed with airway analysis function using two software; Invivo5 (Anatomage) and Romexis (version 3.8.2.R Planmeca). The images were analysed by an examiner with more than three years of experience using this software.

In the Invivo5 software, the airway was measured using the airway segmenting tool as in Figure 1. Then the line was drawn in the middle of the airway space starting from the paranasal sinuses (PNS) level down to the middle of $4^{\text {th }}$ cervical vertebra level in the sagittal view. After the line is drawn, the software will automatically detect the airway within the soft tissue based on the gray values. Once the airway has been defined and the boundaries are well established, the volume of the airway and the minimum area are automatically generated. The setting for airway analysis function can be found in 'volume render' menus as in Figure 2. 
104

In Romexis version 3.8.2.R software, the airway was measured using region growing feature (as in Figure 3). First, a cube was drawn at the area of an airway in a sagittal grayscale view using 'to draw a cube' button. The superior and inferior limit of the cube was at the PNS level and middle of the $4^{\text {th }}$ cervical vertebra. The anterior and posterior limit of the cube was created by certifying that the airway boundaries were included. Then the ' $3 \mathrm{D}$ region growing' button was used to set the parameter to be used. In ' $3 \mathrm{D}$ region growing' window, the 'pre-set' box was set as 'air cavity', the threshold was set at 300, ticked at 'coloured by areas'. Next step was 'select the seed point', this step was needed to allow Romexis to know what type of density to be measured. Click on a space in the airway. Romexis then rendered up the airway and displayed the air volume and the area of the airway. However, in this software, the minimum area is not automatically displayed on sagittal view. Instead, the minimum area was searched by scrolling the axial view.

The measurement was repeated after one week. After all the measurement data was obtained, the data were analyzed using IBM SPSS software (version 23) with t-test to compare the measurement between software and ICC intrarater reliability test to assess the consistency of measurements made by both software in measuring the same quantity. The confidence interval was set at 95\%. For intrarater reliability test, the 'model' used was 'One-Way Random'. Bland \& Altman plot was then plotted to visualize the consistency between measurements.

\section{Results}

Table 1 shows the mean, standard deviation (sd) and the output from t-test analysis for two software. From the table, the mean airway volume and mean minimum area measurement from Romexis software are higher compared to Invivo5 software. However, the standard deviations from Romexis measurements are lower than Invivo5 software. The data also shows that the p-value (for volume and minimum area) was more than 0.05 , therefore, it can be concluded that the mean reading of volume and minimum area is not significantly different between Invivo5 and Romexis.

Table 2 shows the mean, standard deviation and output from intrarater reliability test. From the results obtained, it shows that there was evidence for the repeatability of measurements between two occasions for the software. A copy of the Bland and Altman plot for these data were shown in Figure 4 and Figure 5, which shows good agreement for most cases. For volume measurement, seven were nearer to zero with no outlier, and eight were nearer to zero with one outlier for Invivo5 and Romexis (Figure 4, A and B). For measurement of minimum area, ten were nearer to zero with one outlier and 7 were nearer to zero with one outlier for Invivo5 and Romexis (Figure 5, A and B).

\section{Discussion}

There are currently more than fifteen third-party DICOM viewers mainly for orthodontics, implantology, and oral and maxillofacial surgery was available commercially. Although the reliability, repeatability and accuracy of CBCT machines have been evaluated, testing the reliability of CBCT-related software has not gone further as they differ in terms of the statistical test used.

In this study, two commercially available CBCT software programs that use automatic segmentation to calculate airway volumes were tested. From the t-test analysis, the p-value is equal to 0.914 for both quantity measured. This means that there is no significant difference 
147 between the two software for the airway volume and minimum area. While for ICC test, the 148 intrarater value is more than 0.90 indicating excellent agreement. According to (Fleiss, 1999), 149 the ICC value of 0.75 and above is considered as excellent. So, the correlation values obtained 150 from this study indicate that they are reproducible. The results obtained are supported by other 151 studies (El and Palomo, 2010; Ghoneima and Kula, 2013; Lenza et al., 2010; Feng et al., 2015). 152 (Petdachai and Chuenchompoonut, 2017) had used Romexis software to find the correlation 153 between 3D airway and 2D. They found that the correlation value between theq area in 2D and 154 volume in 3D are very high correlation. While for Invivo software, (Kim et al., 2010) had used this software to measure pharyngeal airway volumes in healthy children with retrognathic mandibles and those with normal craniofacial growth.

The measurement from this software differs slightly due to the fact that these software programs did not use the same methods for calculation of the airway volume and the minimum area. In Invivo5, the segmentation of the airway was based on the point the user click on the airway space and the upper and lower level are follows the shape of the airway. However, in Romexis, the segmentation was done base on the region growing in a cube, thus the upper and lower level does not follow the shape of the airway. This gives a slightly a variation of measurement for both software. The Invivo5 software allows more control where the user can "sculpt out" the desired airway volume from the rest of the 3D structures. The user also can adjust the brightness and opacity values, clean out the unwanted voxels before calculating the final airway volume. The software also lets the user to change the threshold values to obtain a solid airway volume. This also might be the reason to why the measurement of volume using Invivo5 software is more variable than Romexis software.

For automatic segmentation, volume measurements should be done with proper technique and diligence. This is because the measurement changes depending on the image threshold chosen. This is proved by (El and Palomo, 2010). The proper technique also important as the different position will significantly increase or decrease the measurement (Camacho et al., 2014). A study had proved that the CBCT-based 3D analysis gives a better picture of the anatomical characteristics of the upper airways and therefore can lead to an improvement of the diagnosis (Lenza et al., 2010). The automatic segmentation of the airway imaged using CBCT is feasible and this method can be used to evaluate airway cross-section and volume comparable to measurements extracted using manual segmentation (Shi et al., 2006). (Ghoneima and Kula, 2013) had suggested that the three-dimensional CBCT digital measurements of the airway volume and the most constricted area of the airway are reliable and accurate. The use of CBCT imaging for the assessment of the airway can provide clinically useful information in orthodontics and for assessing the airway after surgery. This is proved by (Alsufyani et al., 2017) where they concluded that the use of point-based analysis (from 3D CBCT) measures is better explained the changes in clinical symptoms compared to conventional measures. (Yamashina et al., 2008) had evaluated the reliability of CBCT values and dimensional measurements of oropharyngeal air spaces as compared to multidetector CT on the phantom and clinical patient. They found that the measurement of air spaces with CBCT was quite accurate.

The Bland \& Altman plot created to compare the two measurements that each provides some errors in their measure. The plot also allows the identification of any systematic difference between the measurements or possible outliers. The dotted horizontal lines represent the $95 \%$ confidence limits (limits of agreement). Thus, if the differences between methods were distributed normally, $95 \%$ of the differences from the bias in the sample are expected to be between the upper and lower limit of agreement. As the confidence limits are not exceeded, it 
193 can be concluded that the repeatability of the method is acceptable and the two methods are

194 considered to be in agreement and may be used interchangeably.

\section{Conclusions}

196 From this study, both Romexis 3.8.2.R and Invivo5 software are not giving significantly

197 different reading and are reproducible in their volume and minimum area measurement. If

198 available, both of this software can be used interchangeably.

\section{Acknowledgements}

200 Thank you to all staff involved from dental clinic for their cooperation and support.

\section{References}

202

203

204

205

206

207

208

209

210

211

212

213

214

215

216

217

218

219

220

221

222

223

224

225

226

227

228

229

230

231

232

233
Aboudara C, Nielsen I, Huang JC, Maki K, Miller AJ, Hatcher D. 2009. Comparison of airway space with conventional lateral headfilms and 3-dimensional reconstruction from cone-beam computed tomography. American Journal of Orthodontics and Dentofacial Orthopedics, 135: 468-479. doi:10.1016/j.ajodo.2007.04.043

Alsufyani NA, Noga ML, Witmans M, Major PW. 2017. Upper airway imaging in sleepdisordered breathing : role of cone- beam computed tomography. Oral Radiology 33: 161-169. doi:10.1007/s11282-017-0280-1

Camacho M, Capasso R, Schendel S. 2014. Airway changes in obstructive sleep apnoea patients associated with a supine versus an upright position examined using cone beam computed tomography. The Journal of Laryngology \& Otology 128:824-30.

doi:10.1017/S0022215114001686

Chenin DL. 2015. 3D Imaging of the Upper Airway with Cone Beam Computed Tomography. Available at https://issuu.com/medmark/docs/dsp_fall2015_issuu (accessed 13 April 2017). El H, Palomo JM. 2010. Measuring the airway in 3 dimensions: A reliability and accuracy study. American Journal of Orthodontics \& Dentofacial Orthopedics 137: S50.e1-S50.e9. doi:10.1016/j.ajodo.2009.11.010

Feng X, Li G, Qu Z, Liu L, Nasstrom K, Shi X. 2015. Comparative analysis of upper airway volume with lateral cephalograms and cone-beam computed tomography. American Journal of Orthodontics and Dentofacial Orthopedics, 147: 197-204. doi:10.1016/j.ajodo.2014.10.025 Ghoneima A, Kula K. 2013. Accuracy and reliability of cone-beam computed tomography for airway volume analysis. European Journal of Orthodontics 35: 256-261. doi:10.1093/ejo/cjr099 Glupker L, Kula K, Parks E, Babler W, Stewart K, Ghoneima A. 2015. Three-dimensional computed tomography analysis of airway volume changes between open and closed jaw positions. American Journal of Orthodontics and Dentofacial Orthopedics 147: 426-434. doi:10.1016/j.ajodo.2014.11.025

Iwasaki T, Hayasaki H, Takemoto Y, Kanomi R, Yamasaki Y. 2009. Oropharyngeal airway in children with Class III malocclusion evaluated by cone-beam computed tomography. American Journal of Orthodontics and Dentofacial Orthopedics 136: 318.e1-318.e9. doi:10.1016/j.ajodo.2009.02.017

Kim Y, Hong J, Hwang Y, Park Y. 2010. Three-dimensional analysis of pharyngeal airway in preadolescent children with different anteroposterior skeletal patterns. American Journal of Orthodontics and Dentofacial Orthopedics 137, 306.e1-306.e11. 
234 doi:10.1016/j.ajodo.2009.10.025

235 Lenza MG, Lenza MM, Dalstra M, Melsen B, Cattaneo P. 2010. An analysis of different

236 approaches to the assessment of upper airway morphology : a CBCT study. Orthod Craniofac

237 Res, 13, 96-105.

238 Ogawa T, Enciso R, Memon A, Mah JK, Clark GT. 2005. Evaluation of 3D airway imaging of

239 obstructive sleep apnea with cone-beam computed tomography. Studies in Health Technology

240 and Informatics 111: 365-368.

241 Petdachai S, Chuenchompoonut V. 2017. Prediction of airway volume from lateral cephalograms

242 and correlation among 2D and 3D measurements : A preliminary study. Orthodontic Waves 76:

243 31-39. doi:10.1016/j.odw.2016.11.004

244 Shi H, Scarfe WC, Farman AG. 2006. Upper airway segmentation and dimensions estimation

245 from cone-beam CT image datasets. Int J CARS 1: 177-186. doi:10.1007/s11548-006-0050-8

246 Schendel SA, Hatcher D. 2010. Automated 3-Dimensional airway analysis from cone-beam

247 computed tomography data. Journal of Oral and Maxillofacial Surgery 68: 696-701. Available

248 at https://doi.org/10.1016/j.joms.2009.07.040 (accessed 29 April 2017)

249 Yamashina A, Tanimoto K, Sutthiprapaporn P, Hayakawa Y. 2008. The reliability of computed

250 tomography (CT) values and dimensional measurements of the oropharyngeal region using cone

251 beam CT: comparison with multidetector CT. Dentomaxillofacial Radiology 37: 245-251.

252 doi: $10.1259 / \mathrm{dmfr} / 45926904$

253 Zinsly SR, Moraes LC, Moura P, Ursi W. 2010. Assessment of pharyngeal airway space using

254 cone-beam computed tomography, Dental Press J Orthod 15: 150-158. 


\section{Figure 1}

Display of Invivo5 software for airway analysis in 'section' menu. The airway segmenting tools are shown by the arrow.

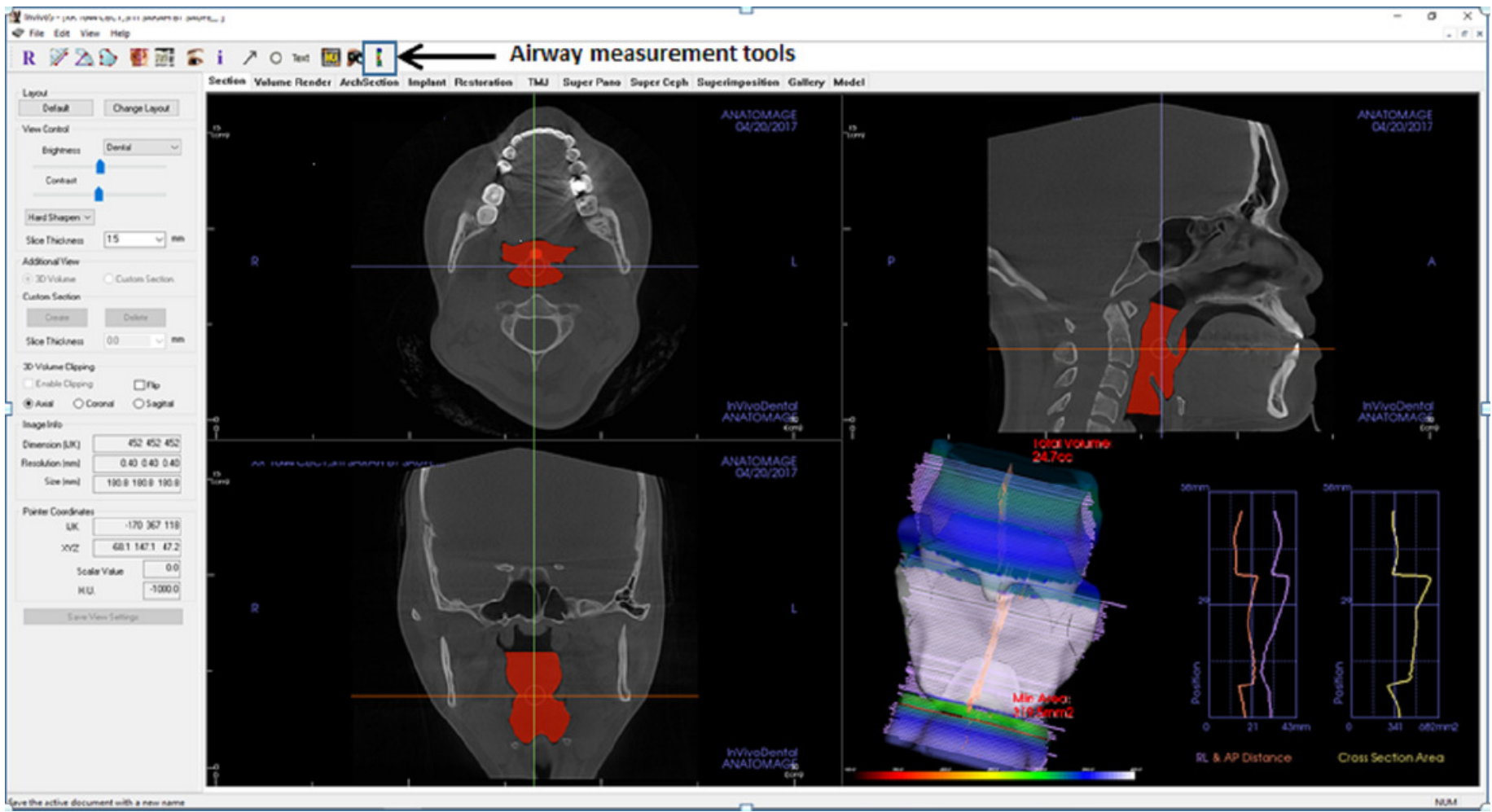




\section{Figure 2}

Display of Invivo5 software for airway analysis in 'volume render' menu. The airway segmenting tools are shown by the arrow.

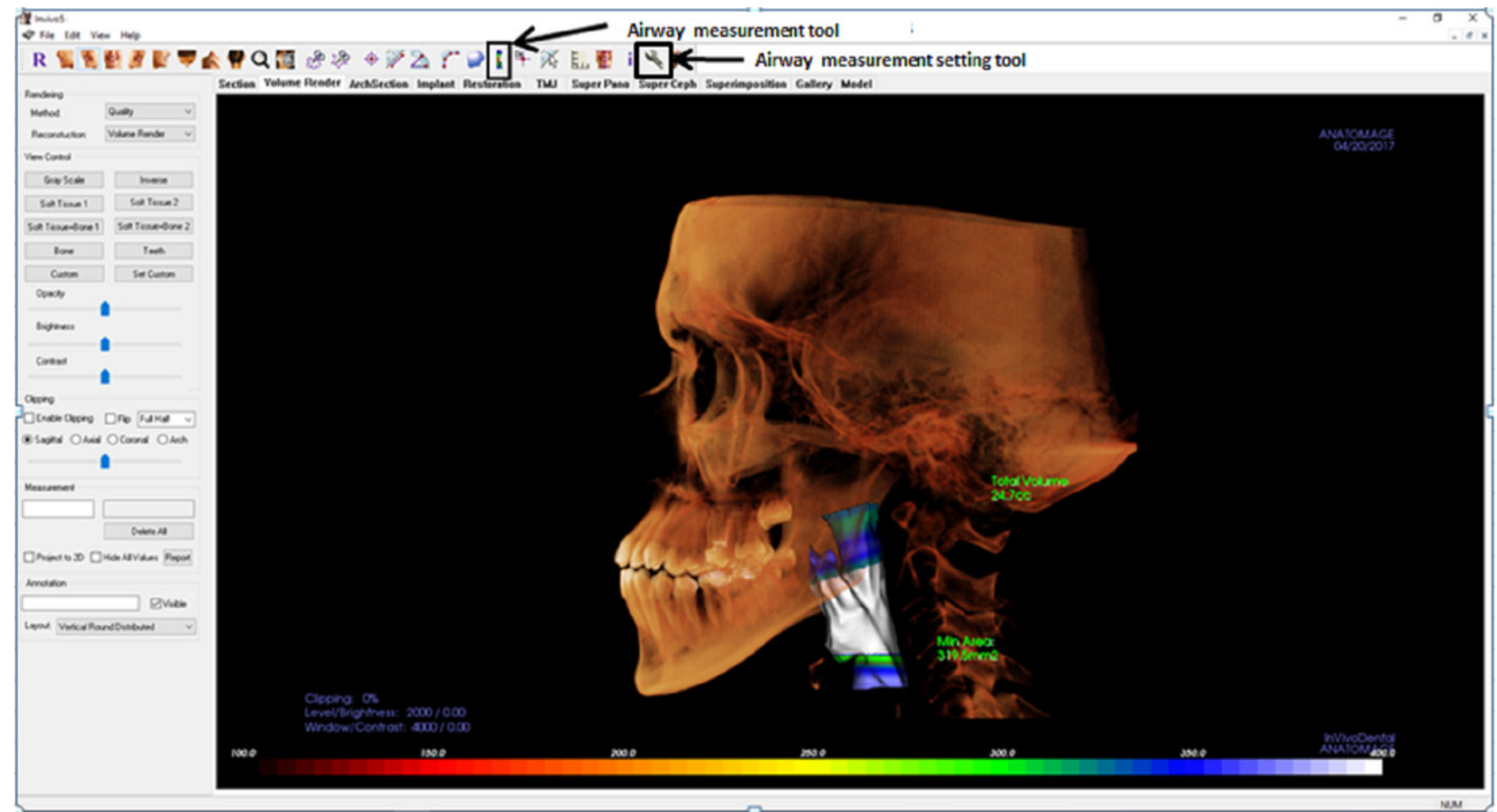




\section{Figure 3}

Display of Romexis (version 3.8.2.R ) software for airway analysis using region growing tools. The button of 'to draw a cube' and '3D region growing' are shown by the arrow.

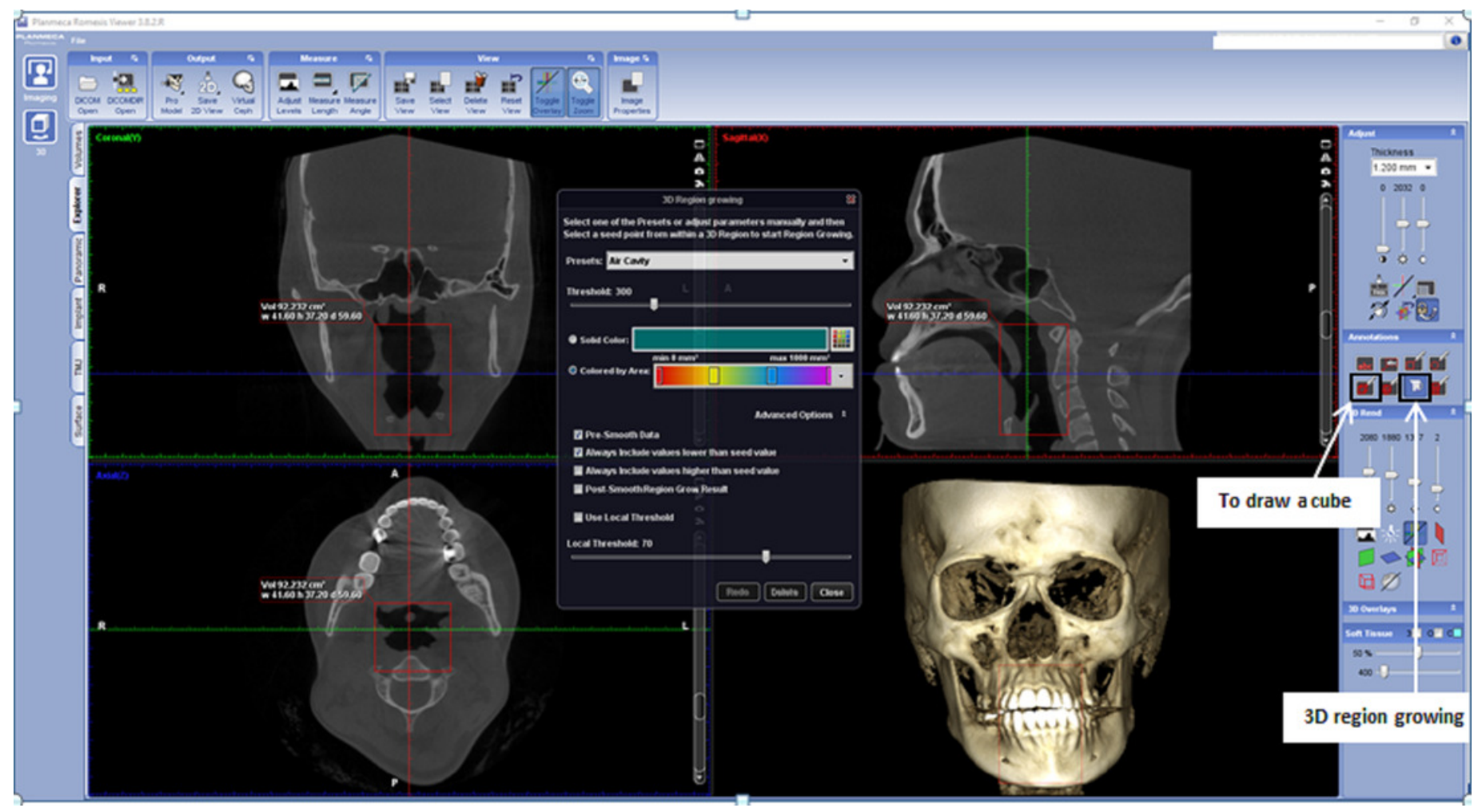


Figure 4

Bland \& Altman plot of $1^{\text {st }}$ and $2^{\text {nd }}$ measurement of volume.
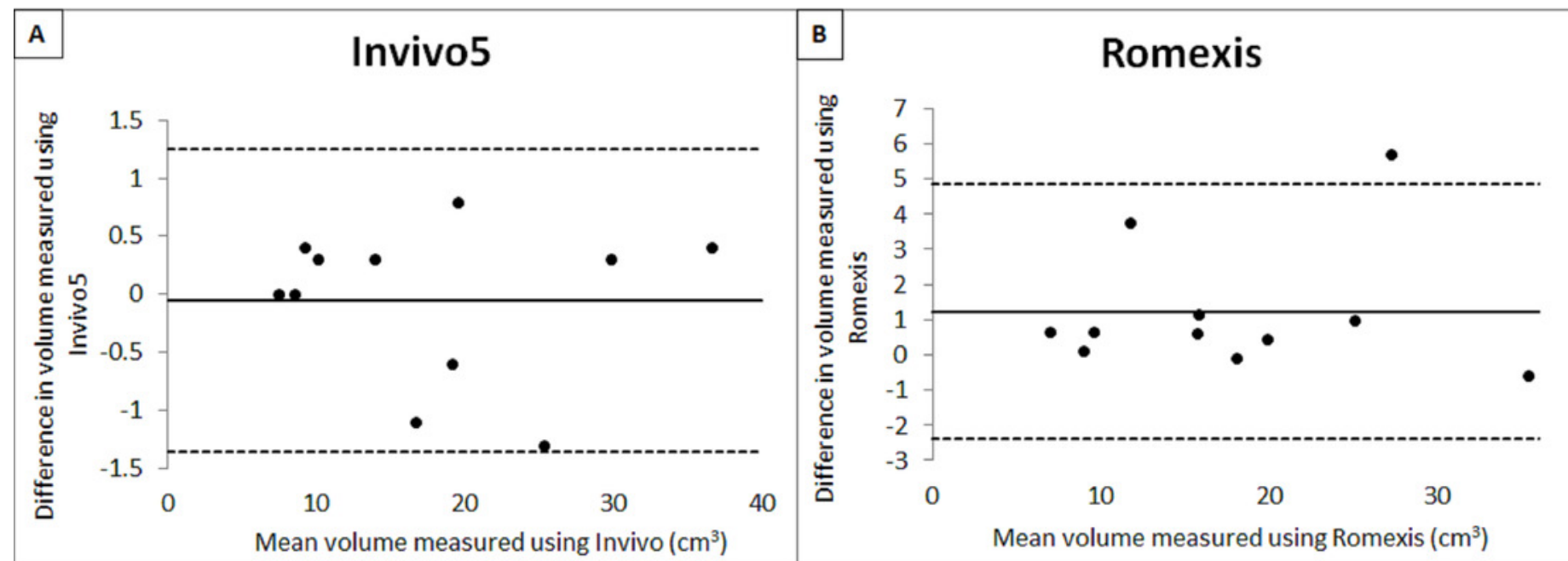
Figure 5

Bland $\&$ Altman plot of $1^{\text {st }}$ and $2^{\text {nd }}$ measurement of min. area.

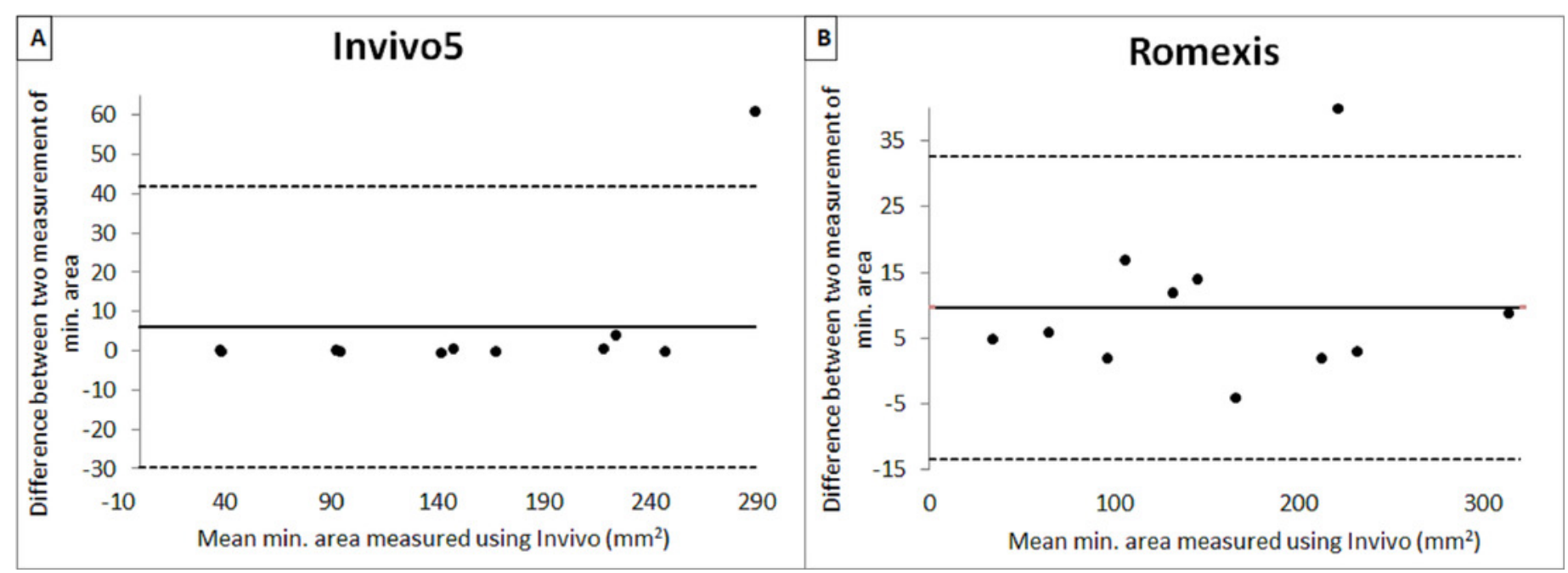




\section{Table 1 (on next page)}

T-test for airway volume and minimum area. 
TABLE 1. T-test for airway volume and minimum area.

\begin{tabular}{lllll}
\hline Quantity & Method & Mean & $\begin{array}{l}\text { Std. } \\
\text { Deviation }\end{array}$ & $\begin{array}{l}\text { Sig. (2- } \\
\text { tailed) }\end{array}$ \\
\hline \multirow{2}{*}{ Volume, $\mathrm{cm}^{3}$} & Invivo5 & 17.83 & 9.48 & .914 \\
& Romexis & 18.26 & 8.86 & \\
\multirow{2}{*}{ min.area, $\mathrm{mm}^{2}$} & Invivo5 & 156.97 & 89.44 & .914 \\
& Romexis & 161.00 & 83.88 & \\
\hline
\end{tabular}

2

3 


\section{Table 2 (on next page)}

Intrarater reliability test (ICC) for airway volume and minimum area. 
TABLE 2. Intrarater reliability test (ICC) for airway volume and minimum area.

\begin{tabular}{|c|c|c|c|c|c|}
\hline & Mean & $\begin{array}{l}\text { Std. } \\
\text { Deviation }\end{array}$ & $\begin{array}{l}\text { Intraclass } \\
\text { Correlation (r) }\end{array}$ & $\begin{array}{l}\text { Lower } \\
\text { Bound }\end{array}$ & $\begin{array}{l}\text { Upper } \\
\text { Bound }\end{array}$ \\
\hline \multicolumn{6}{|l|}{ Invivo5 volume, $\mathrm{cm}^{3}$} \\
\hline $1^{\text {st }}$ measurement & 17.83 & 9.48 & \multirow[b]{2}{*}{0.998} & \multirow[b]{2}{*}{0.992} & \multirow[b]{2}{*}{0.999} \\
\hline $2^{\text {nd }}$ measurement & 17.87 & 9.52 & & & \\
\hline \multicolumn{6}{|c|}{ Romexis volume, $\mathrm{cm}^{3}$} \\
\hline $1^{\text {st }}$ measurement & 18.26 & 8.86 & \multirow[b]{2}{*}{0.970} & \multirow[b]{2}{*}{0.899} & \multirow[b]{2}{*}{0.992} \\
\hline $2^{\text {nd }}$ measurement & 17.037 & 8.71 & & & \\
\hline \multicolumn{6}{|c|}{ Invivo5 min. area, $\mathrm{mm}^{2}$} \\
\hline $1^{\text {st }}$ measurement & 156.97 & 89.44 & \multirow[b]{2}{*}{0.976} & \multirow[b]{2}{*}{0.918} & \multirow[b]{2}{*}{0.993} \\
\hline $2^{\text {nd }}$ measurement & 150.91 & 79.33 & & & \\
\hline \multicolumn{6}{|c|}{ Romexis $\min$. area, $\mathrm{mm}^{2}$} \\
\hline $1^{\text {st }}$ measurement & 161.00 & 83.88 & \multirow{2}{*}{0.984} & \multirow{2}{*}{0.945} & \multirow{2}{*}{0.996} \\
\hline $2^{\text {nd }}$ measurement & 151.36 & 81.83 & & & \\
\hline
\end{tabular}

2

3 